\title{
Reconstruction of Scalp Defects Using Non-Microsurgical Techniques
}

\author{
AMR MOHAMED ELHUSSINY KHATER, M.D. and AHMED ELSAAID ZAYED, M.D. \\ The Department of Plastic Surgery, Faculty of Medicine, Mansoura University, Mansoura, Egypt
}

\begin{abstract}
Introduction: Skin loss of the scalp with exposed underlying structures are reconstructed by plastic surgeons. In this study, we highlight the non-microsurgical reconstructive options.

Patients and Methods: A retrospective study was conducted where data of 13 cases who underwent immediate scalp reconstruction were recorded and analyzed.

Results: The causes of scalp defects were either congenital (7.7\%), traumatic (53.8), electrical burn $(7.7 \%)$ or after tumor excision $(30.8 \%)$. The extent of the scalp defects ranged from $20 \mathrm{~cm} \mathrm{X} 8 \mathrm{~cm}$ to $3 \mathrm{~cm} \mathrm{X} 4 \mathrm{~cm}$. The most affected regions were temporal, parietal, occipital and forehead. The reconstructive procedures were transposition flaps, rotation flaps, skin graft, drill holes, integra, pinwheel flap and Ortichoa flaps.

Discussion: To obtain successful scalp reconstruction, plastic surgeons need to understand the diversity of scalp defects and mastering many reconstructive options. When microsurgical reconstruction of scalp is not available or contraindicated, a number of more simplified techniques can achieve stable and efficient results.

Conclusion: A variety of reconstructive requirements and choices should be considered when undertaking scalp reconstruction. An algorithm is needed for management of different defects of the scalp. Defect size, location and depth are the critical factors for the choice of the surgical technique.
\end{abstract}

Key Words: Scalp - Skull - Outer table - Integra - Drilling.

\section{INTRODUCTION}

Plastic surgeons reconstruct a wide range of defects of the scalp and cranial vault. The etiology of these defects may be due to congenital, traumatic or neoplastic causes [1]. The goals of reconstruction of scalp defects are to achieve protection of underlying central nervous system and obtaining an aesthetically accepted shape of the scalp [2].

Reconstructive options for these defects include skin grafts [3], local flaps [4] and free flaps [5]. Defects with intact underlying periostium can be reconstructed with skin grafts while other wounds with exposure of underlying calvarial bones, dura matter or brain tissues require flap coverage. Acellular dermal matrix and skin graft has been used in scalp reconstruction with successful outcomes [6].

Tissue expansion was used in reconstruction of scalp defects successfully [7]. However, it is not applicable to traumatic cases and we did not include cases managed by tissue expansion in this study.

The surgical application of free flaps for repair of scalp defects was documented [8]. This reconstructive option is not discussed in this article. In this article, we will focus on the use nonmicrosurgical techniques that are involved in reconstruction of scalp defects, their benefits and limitations.

\section{PATIENTS AND METHODS}

This is a retrospective study for 13 cases who underwent immediate reconstruction of scalp defects from October 2015 to May 2019. The causes of scalp defects were congenital, traumatic or after tumor ablation. Institutional Review Board (IRB) approval was obtained.

The inclusion criteria included patients with scalp defects and an informed patient consent was obtained after explaining the recommended surgical procedure, its benefits, limitations and expected outcomes.

The following procedures were done:

- Partial thickness skin grafts: Grafts were used to repair of scalp wounds when vascularized beds (periosteum, aponeurosis or subcutaneous tissues) are available.

- Local flaps with or without skin graft: Different local flaps configuration were used in scalp wounds reconstruction including transposition, rotation Fig. (1) or advancement flaps. 
- Pin wheel flaps (multiple rotation and transposition flaps): This technique was applied to cover to medium defects especially at the temporal region or vertex Fig. (2).

- Ortichoa technique: This technique was applied to reconstruct medium to large defects at the vertex.

- Drilling of the diplopic space and skin grafting Fig. (3): To expose the diplopic space, the outer table of the skull was drilled. After dressing changes, healthy granulation tissues are formed and creeped to coat the outer table bones. In a second surgery, we applied Thiersch skin grafts

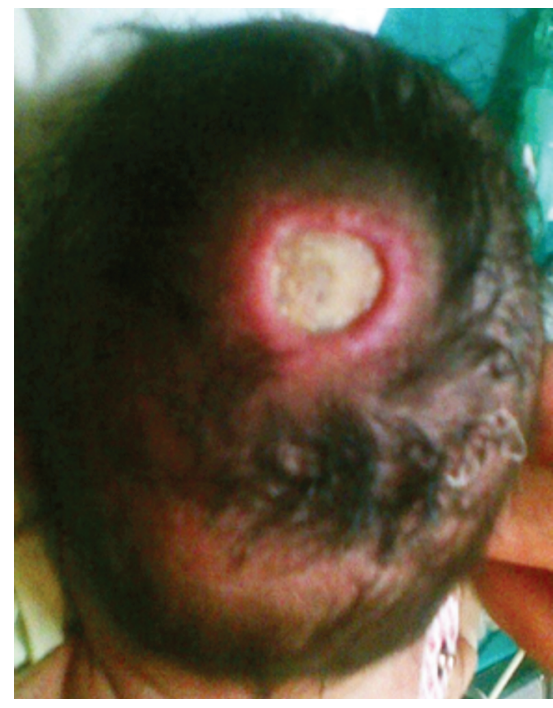

(A) were applied to cover the granulation tissues. Artificial dermal regeneration template (Integra):

Artificial skin was applied to complicated wound when there is no available flap coverage and the dura was exposed. After 3 weeks, we discarded the external silicone layer and a meshed ultra-thin skin graft was applied to the healthy bed containing the integrated dermal component of the Integra.

We recorded the following data for each patient: Age, sex, cause of scalp defects, site and size of scalp defects, type of surgery performed and complication rates.

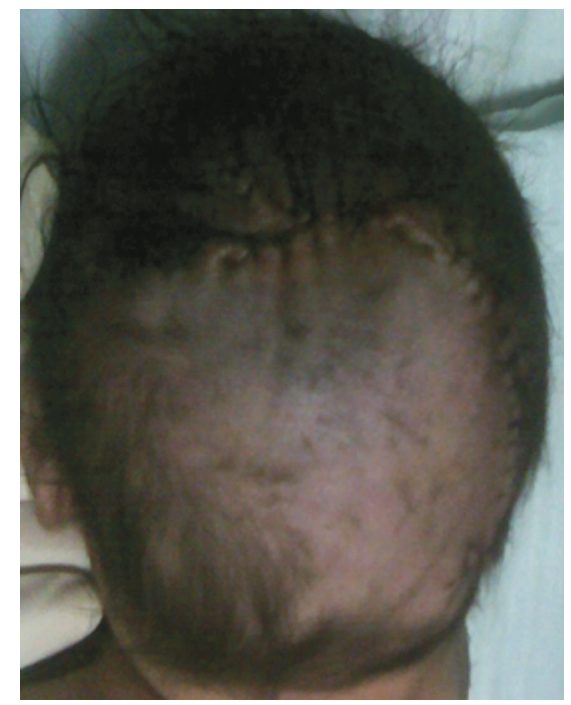

(B)

Fig. (1): Case number 5. (A): Pre-operative photo of a case with congenital scalp defect at the vertex. (B): Three weeks post-operative view where rotation flap was done.

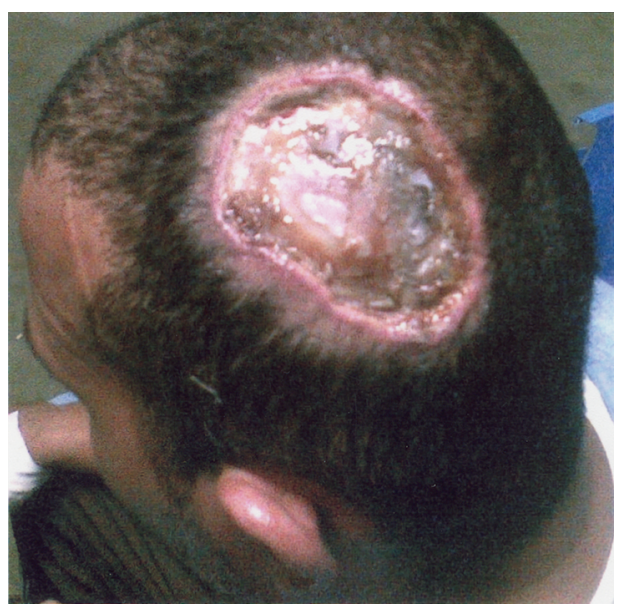

(A)

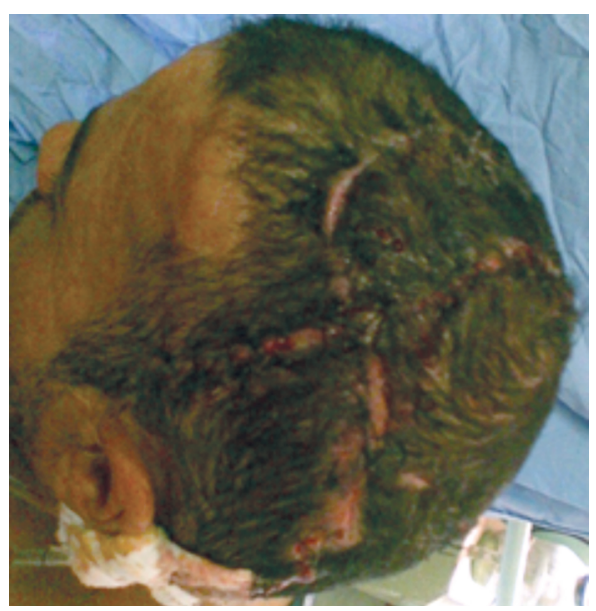

(B)

Fig. (2): Case number 3. (A): Pre-operative photo of a case with post electrical burn scalp defect at the temporal region. (B): 2 months post-operative view. 

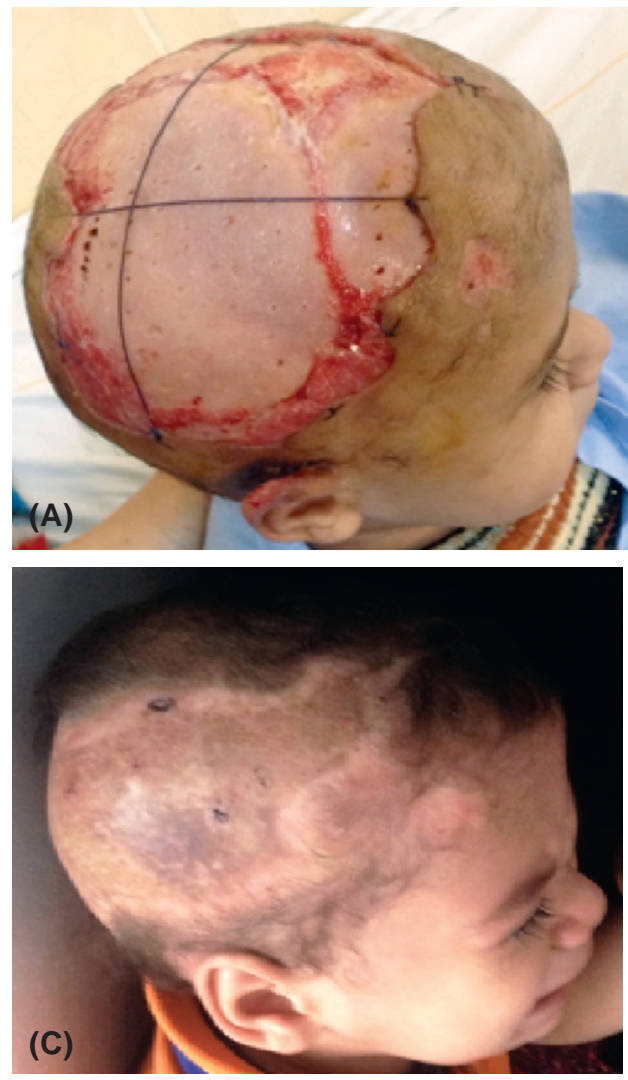

RESULTS

In this study, we operated 13 cases, 12 cases $(92 \%)$ were males and one case $(8 \%)$ was female. The range of the age of our patients was from 2 weeks to 72 years (average 34.1 years). The etiology of scalp wounds defects was either congenital in one case $(7.7 \%)$, traumatic in seven cases (53.8), in one case electrical burn $(7.7 \%)$ or after tumor excision in four cases $(30.8 \%)$.

The dimensions of the scalp defects were from $20 \mathrm{~cm} \mathrm{X} 8 \mathrm{~cm}$ to $3 \mathrm{~cm} \mathrm{X} 4 \mathrm{~cm}$. The following regions of the scalp were affected temporal ( 8 cases),

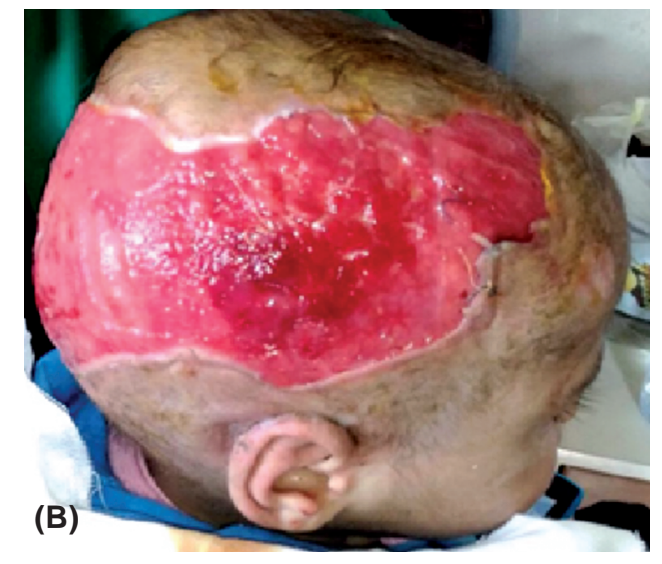

Fig. (3): Case number 4. (A): Pre-operative photo of a case with traumatic scalp avulsion with exposed right temporal and parietal bones. (B): Post-operative view of the first surgery where transposition flap was done to cover the parietal bone and graulation tissues was formed at the temporal bones after performing multiple drill holes and dressing changes. (C): 6 months post-operative view of second surgery where skin grafts were applied to cover granulation tissues overlying the temporal bones.

parietal (7 cases), occipital (2 cases) and forehead (one case). The reconstructive procedures were skin graft (in 5 cases), rotation flaps (utilized in 4 cases), transposition flaps (in 4 cases), drill holes (in 3 cases), (Integra) artificial dermal regeneration template (in one case), pinwheel flap (in one case) and Ortichoa flaps (in one case). Table (1) shows patients demographic data. Early complication was delayed wound healing in one case. Late complication included dog ear formation in one case and tumor recurrence in one case. An algorithm is proposed for management of various scalp defects Fig. (5).

Table (1): Patients' demographic data.

\begin{tabular}{|c|c|c|c|c|c|c|}
\hline & Age & Sex & Cause & Site & Size & Surgery \\
\hline 1 & 72 & M & Tumor meningioma & Temporal-Occipital-Parietal & $20 * 8$ & Integra-drill holes-skin graft \\
\hline 2 & 42 & $\mathrm{~F}$ & Tumor fibroma & Temporal- & $12 * 7$ & Skin graft \\
\hline 3 & 25 & M & Electrical burn & Temporal & $10 * 5$ & Pinwheel flaps \\
\hline 4 & 4 & M & Trauma & Parietal-temporal & $18 * 10$ & Drill holes-transposition flap-skin grafts \\
\hline 5 & 2 weeks & M & Congenital & Parietal & $4 * 3$ & Rotation flap \\
\hline 6 & 65 & M & Tumor BCC & Parietal & $8 * 7$ & Ortichoa flaps \\
\hline 7 & 25 & M & Trauma & Temporal & $5 * 4$ & Rotation flap \\
\hline 8 & 35 & M & Trauma & Temporal & $4 * 3$ & Rotation flap \\
\hline 9 & 30 & M & Trauma & Parietal & $8 * 5$ & Rotation flaps \\
\hline 10 & 52 & M & Trauma & parietal-temporal & $12 * 7$ & Transposition flaps \\
\hline 11 & 7 & M & Trauma & Temporal-forehead & $10 * 4$ & Drill holes and skin graft \\
\hline 12 & 65 & M & Tumor & Parietal & $15 * 10$ & Transposition flaps and skin graft \\
\hline 13 & 21 & M & Trauma & Occipital & $5 * 7$ & Transposition flaps \\
\hline
\end{tabular}




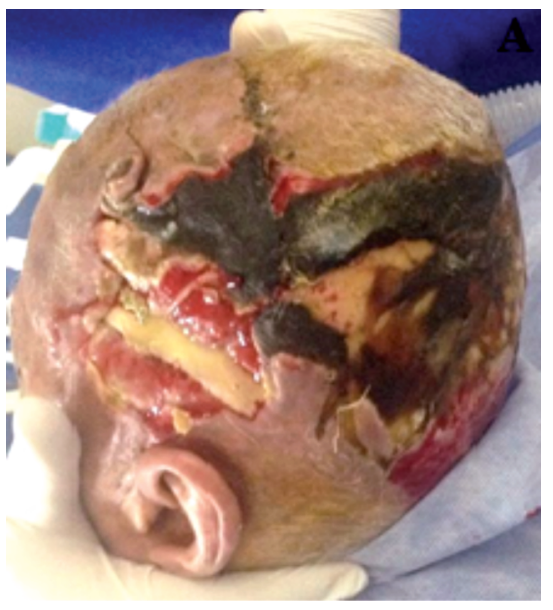

(A)

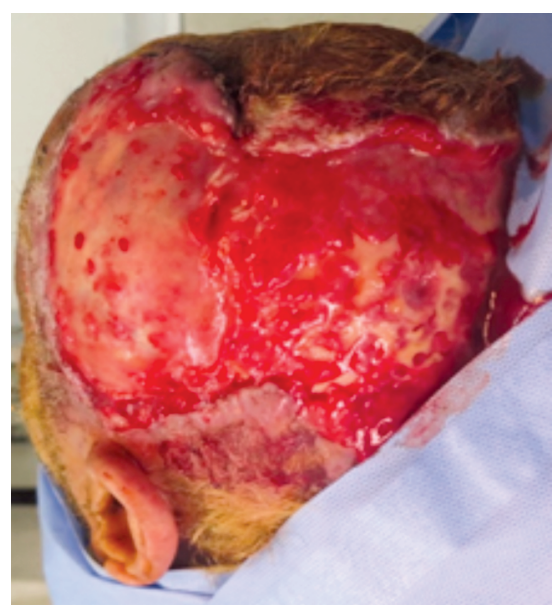

(D)

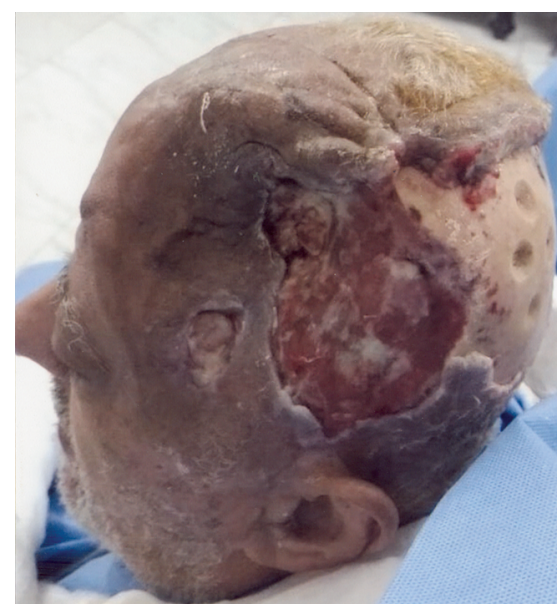

(B)

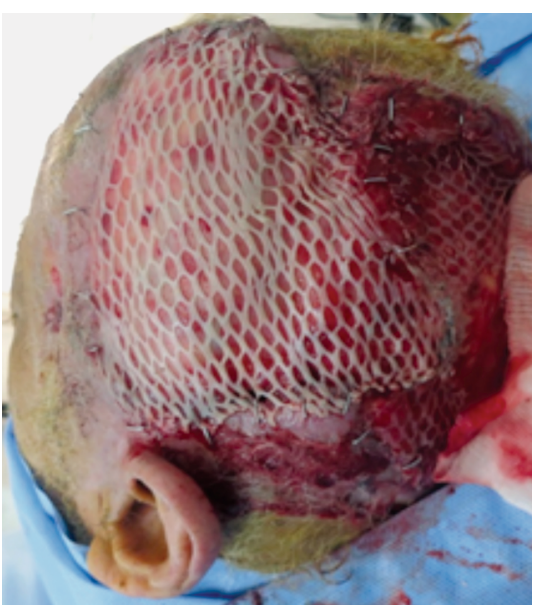

(E)

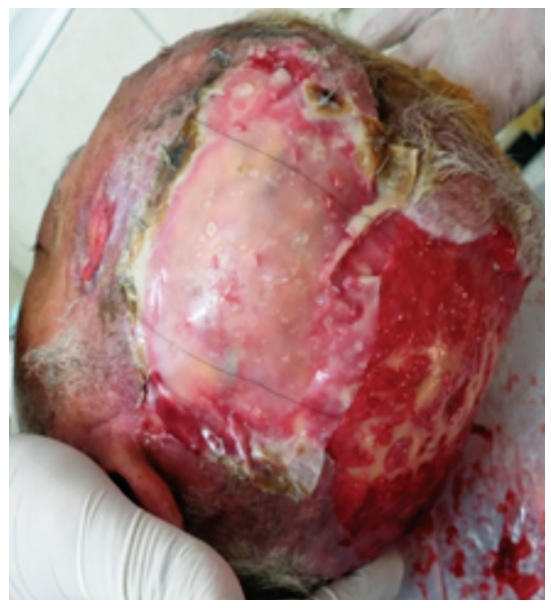

(C)

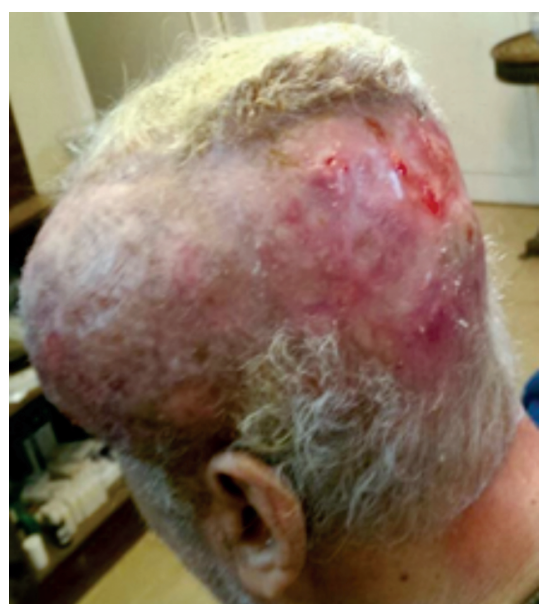

(F)

Fig. (4): Case number 5. (A): Pre-operative photo of a 72 years old male patient who had previous resection of meningioma in the temporal region. A transposition flap and split rib graft were used to reconstruct the temporal defect. Unfortunately, ischemic skin flaps and graft failure occurred. (B): Post-operative view of the first operation where debridement of necrotic tissues and drill holes in the occipital region were done. There is exposed meninges in the temporal region. (C): Post-operative view of the second surgery where Integra was applied to the exposed meninges. (D): Intraoperative view of the third surgery where the outer silicone layer of the Integra was removed and successful take of the dermal layer of the Integra was confirmed. (E): Immediate post-operative view after application of meshed skin grafts. (F): 6 months post-operative view.

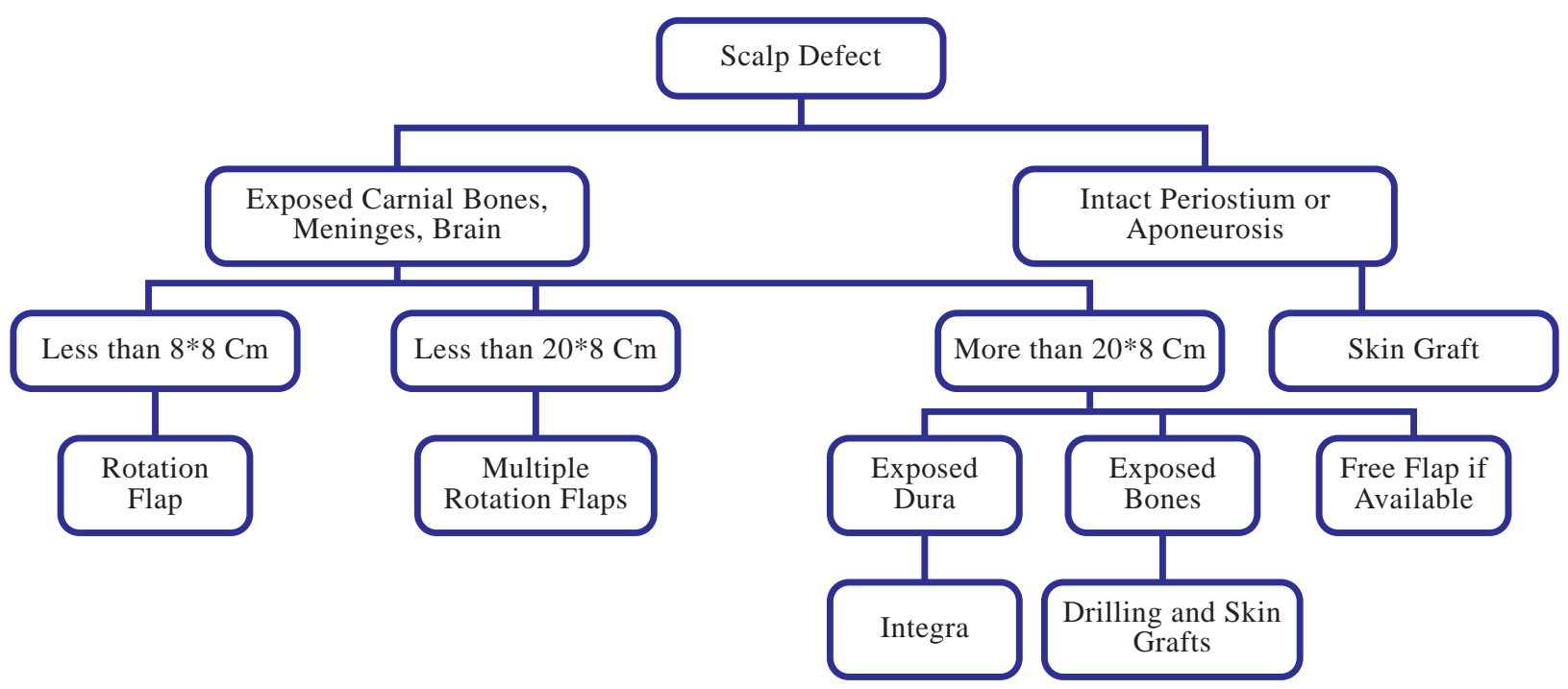

Fig. (5): An algorithm for scalp reconstruction. 


\section{DISCUSSION}

Coverage of soft tissues wounds of the scalp is the task of the plastic surgeons [9]. The reconstructive options include healing by dressing changes and secondary intention, healing by direct suturing and primary closure, the use of skin grafts, local scalp flaps, regional pedicled flaps and microvascular free flaps [10].

In the current study, we did not include any free flaps. Free flaps are the best option for covering total or near total scalp defects. Latissimus Dorsi [11], omentum [12], radial forearm [13] and anterolateral thigh [14] free flaps have been utilized successfully for coverage of scalp defects. However, there are some disadvantages and limitations. Extreme of age, presence of co-morbid conditions and patients willing to have a less extensive surgery are the major contraindications free flap usage. In addition, any other tissues in the body cannot match the unique character of the scalp tissues of having a dense population of hairs.

Regional flaps like pedicled Latissimus Dorsi [15] or pedicled trapezius [16] cannot reach all areas of the scalp specially the vertex and supply tissues with questionable vascularity. The distal part of the flap is the most needed tissue for reconstruction and the tissue most far from the pedicle with the lowest perfusion.

Skin grafts have the benefits of being an easy technique with rapid healing properties when applied to a well-vascularized bed [17]. When we are not confident about safety margin after tumor clearance, skin grafts allow early and easy detection of tumor recurrence. However, it has the limitations of poor take if applied to exposed cortical bones and the presence of post-operative alopecia and donor site morbidity.

Local scalp flaps can reconstruct scalp defects up to $8 \times 8 \mathrm{~cm}$ with direct closure. The combination of multiple rotations' flaps with or without skin grafts can cover extensive scalp defects. The advantages of usage of local scalp flaps are an easy rapid technique, short hospital stay and limited alopecia just at the suture lines. It is major disadvantages is the long incision lines with extensive undermining [18].

Healing by direct suture closure is possible only in limited defect sizes less than $3 \mathrm{~cm}$ [19]. Healing by secondary intension and dressing changes is time consuming technique and has a poor cosmetic outcomes [20]. In this study, we did not include cases managed by the previous two techniques.

The technique of removal of outer table of skull to speed the process of granulation tissue formation and skin grafting has been used in management of massive scalp loss [21]. We used this technique in three cases when no local flaps are available to cover the skull bones and free flap cannot be used due to extreme of age or anesthesia contraindications. Despite the need of two surgeries, stable wound coverage was obtained successfully.

Dermal regeneration template is used successfully in coverage of complex scalp defects [22]. We used it in one case to cover the exposed dura. After 3 weeks, a second surgery was needed to cover the successfully taken dermal component with partial thickness skin grafts. We did not observe any tissue breakdown or infection in this artificial template.

In this study, we succeeded to cover extensive and complicated scalp defects without the use of microsurgical techniques. The combination of different reconstructive solutions can achieve good results without the exposure of the risks and limitation to microsurgical reconstruction.

\section{Conclusion:}

Efficient scalp reconstruction needs a detailed and accurate understanding of the anatomy of the different components of the scalp and mastering a variety of reconstructive options in order to be able to manage various scalp defects. When microsurgical reconstruction is not available or contraindicated, a number of more simplified techniques can be used effectively.

\section{REFERENCES}

1- Lin S.J., Hanasono M.M. and Skoracki R.J.: Scalp and calvarial reconstruction. Semin. Plast. Surg., 22 (4): 28193, 2008.

2- Freund R.M.: Scalp, calvarium and forehead reconstruction. In: Aston SJ, Beasley RW, Thorne CHM, eds. Grabb and Smith's Plastic Surgery. Philadelphia, PA: LippincottRaven: 473, 1997.

3- Hilton C.M.H. and Hölmich L.R.: Full-or Split-Thickness Skin Grafting in Scalp Surgery? Retrospective Case Series. World J. Plast. Surg., 8 (3): 331-7, 2019.

4- Schonauer F., Abbate V., Dell'Aversana Orabona G., et al.: Hand Doppler flowmetry for surgical planning of pedicled flap in extensive full-thickness scalp reconstruction. Surg. Oncol., 25; 32: 49-56, 2019.

5- Sokoya M., Misch E., Vincent A., et al.: Free Tissue Reconstruction of the Scalp. Semin. Plast. Surg., 33 (1): 67-71, 2019. 
6- Chun Y.S. and Verma K.: Single-stage full-thickness scalp reconstruction using acellular dermal matrix and skin graft. Eplasty., 11: e4, 2011.

7- Baker S.R. and Swanson N.A.: Tissue expansion of the head and neck: Indications, technique, and complications. Arch. Otolaryngol. Head Neck Surg., 116 (10): 1147-53, 1990.

8- Lamaris G.A., Knackstedt R., Couto R.A., et al.: The Anterolateral Thigh Flap as the Flap of Choice for Scalp Reconstruction. J. Craniofac. Surg., 28 (2): 472-6, 2017.

9- Newman M.I., Hanasono M.M., Disa J.J., et al.: Scalp reconstruction: A 15-year experience. Ann. Plast. Surg., 52 (5): 501-6, 2004.

10- Leedy J.E., Janis J.E. and Rohrich R.J.: Reconstruction of acquired scalp defects: An algorithmic approach. Plast. Reconstr. Surg., 116 (4): 54e-72e, 2005.

11- Arai H., Yanai A., Nishida M., et al.: Reconstruction of Scalp and Cranium Defect Utilizing Latissimus Dorsi Musculocutaneous and Serratus Anterior Muscle Free Flaps with Interpositional Anastomosis of T-Shaped Flap Artery Case Report. Skull base surgery, 5 (2): 117-21, 1995.

12- Sierakowski K., Solanki N.S. and Riddell P.: Total Scalp Excision and Reconstruction Using a Free Omental. Flap. Eplasty., 15: ic58, 2015.

13- Chicarilli Z.N., Ariyan S. and Cuono C.B.: Single-stage repair of complex scalp and cranial defects with the free radial forearm flap. Plast. Reconstr. Surg., 77 (4): 577 85, 1986.

14- Lutz B.S.: Aesthetic and functional advantages of the anterolateral thigh flap in reconstruction of tumor-related scalp defects. Microsurgery, 22 (6): 258-64, 2002.

15- Jeong W.S.1, Roh J.L. and Kim E.K.: Extensive scalp reconstruction after repeated failure of free tissue transfer with a pedicled latissimus dorsi flap. J. Craniofac. Surg., 25 (3): 1103-5, 2014.

16- Yang H.J., Lee D.H., Kim Y.W., et al.: The Trapezius Muscle Flap: A Viable Alternative for Posterior Scalp and Neck Reconstruction. Arch. Plast. Surg., 43 (6): 529-35, 2016.

17- Hilton C.M.H. and Hölmich L.R.: Full-or Split-Thickness Skin Grafting in Scalp Surgery? Retrospective Case Series. World J. Plast. Surg., 8 (3): 331-7, 2019.

18- Costa D.J., Walen S., Varvares M., et al.: Scalp Rotation Flap for Reconstruction of Complex Soft Tissue Defects. J. Neurol. Surg., 77: 32-7, 2016.

19- Tolhurst D.E., Carstens M.H., Greco R.J. and Hurwitz D.J.: The surgical anatomy of the scalp. Plast. Reconstr. Surg., 87 (4): 603-12, 1991.

20- Becker G.D., Adams L.A. and Levin B.C.: Secondary intention healing of exposed scalp and forehead bone after Mohs surgery. Otolaryngol. Head Neck Surg., 121 (6): 751-4, 1999.

21- Sheridan R.L., Choucair R.J. and Donelan M.B.: Management of massive calvarial exposure in young children. J. Burn Care Rehabil., 19 (1 Pt 1): 29-32, 1998.

22- Khan M.A., Ali S.N., Farid M., et al.: Use of dermal regeneration template (Integra) for reconstruction of fullthickness complex oncologic scalp defects. J. Craniofac. Surg., 21 (3): 905-9, 2010. 